\title{
Aesthetic evaluation of restaurants facade through public preferences and computational aesthetic approach
}

\author{
Herry Santosa $^{\mathrm{a}^{*}}$, Nur Fauziah ${ }^{\mathrm{b}}$ \\ ${ }^{a}$ Architecture Department, Faculty of Engineering, Brawijaya University, \\ Jl. MT.Haryono 167 Malang-65145, Indonesia \\ ${ }^{b}$ Alumni of Magister Architecture of Built Environment, Faculty of Engineering, Brawijaya University, \\ Jl. MT.Haryono 167 Malang-65145, Indonesia \\ *Corresponding author. Tel.: +62-341-567486; fax: +62-341-567486. \\ E-mail address: herrysantosa@ub.ac.id
}

\begin{abstract}
The visual quality of urban space represents the character of the city. Urban space should be able to deliver satisfying aesthetic and sensory experience. The visual quality of urban space formed by the visual signs representing an urban image and influencing the spatial behavior of every individual. A good urban space will encourage the emergence of good perception and meaning, prompting the community to produce a good reaction on its urban spaces. The involvement of public participation in the evaluation and assessment of the visual aesthetics of the urban image is needed to establish a good urban space. This paper investigates the rapid growth of restaurant in the commercial area corridor adjacent to the education campus area in Malang City. Both the location factor and consumers of college students has stimulated the growth of the variety building facade appearances and led to the dominance of contemporary architectural styles. In furtherance of bringing the visual quality of a good urban image, the study on aesthetic aspects is conducted to control the quality visual appearance of the building facade. This study combines the method of public preferences through the Semantic Differential Scales with the computational aesthetic methods through the applications of Interfaces Aesthetic Measurement (IAM) with 13 variables of aesthetic. The results of this study stated that the aesthetic value assessment of building facade restaurants in study area showed a positive value. Furthermore, the comparison of assessment values between the methods of public preferences with the computational aesthetics indicates similarities.
\end{abstract}

Keywords: urban image; building façade; public preferences; computational aesthetics

\section{Introduction.}

In the study and planning of urban areas, it is greatly essential to observe the growth and the development of architectural embodiment in the street corridor. Street corridor reflects the quality of urban space and represents the character of the city at once. The city should provide its citizens with a continuously satisfying aesthetic and sensory experience (Porteous, 1996). It means that the aesthetic experience is very important for making cityscape. City planners must be able to accommodate the creation of urban spatial that is able to ensure the creation the experience a comfortable and satisfying for the community. 


\subsection{Visual aesthetic evaluation of building facade in urban space}

The creation of great visual quality of urban spaces is aimed to raise up a good urban image. Every person possesses own perception and association, either in the positive or negative, to the surrounding environment as well as to every element that shaped image in the neighborhood (Nasar, 1998). The creation of good urban image will encourage the emergence of good perception and meaning, thus encourages the public to produce a good reaction on its urban spaces. Evaluation of urban image in the street corridor involves the assessment of subjective feeling, which contains two variables: the visual aspect in the form of urban space and community responses to visual evaluation. The visual aspect is the independent variable that contains the physical characteristics and associated with the aspects of geometry. While the community responses to visual evaluation are the dependent variable associated with the community response to the visual characteristics. Every place has different goals and a different purpose, thus demanding a different characteristic shape of environments. An understanding of the diversity of values in the city that developed and owned by the community in a particular region, require an appropriate identification. The process of identification and investigation of community values can be performed by distributing questionnaires so that people can express their opinions independently.

One of the objectives of the evaluation of urban image is to control the quality of visual appearance of the building, in order to create continuity of visual aesthetic as well as supporting a good urban image. One control implementation is located in the physical form of the building that forms urban space corridor. The characteristics or particularities of the most easily observed are a physical form because the visual impression is something that is easy to be absorbed and grasped by the human memory (Lynch, 1960). The physical form of the building is defined in the characteristic visual appearance of the building facade, bound in the visual continuity of a one interwoven architectural style in the corridor or urban area. At the level of the procedures or research methods, the study of the order of building facade on the street corridor can be divided at each building facade.

The aesthetic value of a landscape is embodied in its visual merits (Vining \& Stevens, 1986). The visual quality can be seen through visual clues as images perception that is capable perceived with the eye (sign) (Ching, 2012). The visual quality can also be seen through the aspects of visual design, namely: figure-ground, continuity, sequence, repetition and rhythm, balance, shape, size, scale, proportion, pattern, texture, color, hierarchy, dominance, transparency, direction, similarity, motion, time and sensory quality (Rubenstein, 1980). The visual character formed by the order or the interactions and composition of the elements of shape, line, color, texture, scale and proportion (Smardon, Palmer, \& Felleman, 1986).

\subsection{Environmental aesthetics and computational aesthetic}

The efforts to control the diversity of visual quality of building facade can be performed by conducting research on aesthetic aspects. There are two potential approaches to performing the aesthetic quality evaluation of the building facade, namely the environmental aesthetics and computational aesthetic. Environmental aesthetics as an aesthetic understanding of the environmental influences which affects and translates an understanding of the design environment that benefit the public (Wohlwill, 1976). The environmental aesthetic is a scientific methodology that assists explain the relationship between physical stimuli and the human response (Nasar, 1988). Environmental aesthetics, employ the public preferences method by involving a measurement scale of the semantic differential scales that commonly used to measure the depth of the meaning of a design (Cass \& Hershberger, 1972). Semantic Differential is descriptive assessments obtained by using a bipolar scale from the opposite attributes. Based on the semantic differential scales, the assessment of public preferences utilizes a questionnaire containing a set of measurement scales of the aesthetic aspects of the building facade.

Meanwhile, the computational aesthetic approach bases on visual measurements of a digital image that can be examined by a computer. Digital image consists of the smallest components called pixels or picture elements (Gonzalez, 2002). This approach utilizes the application of Interfaces Aesthetic Measurement (IAM) developed by Purnomo (Purnomo, 2009). The assessment of digital image in the IAM applications is performed by dividing the digital image into entities with specific characteristics and attributes. Entities are defined as continuous pixel groups 
and possess a particular attribute that led to the unification of the pixels into an entity. The application of IAM has 13 aesthetic variables that can be measured based on the attributes of an interface entity (Ngo et al, as cited in Purnomo, 2009).

The combined use of the two approach methods is aimed to compare the result between the assessment of public preferences and the scoring of the IAM application toward the aesthetic value of building facade restaurants in the commercial street corridor, Malang. This research is also intended to measure the level of accuracy of the use of the computational aesthetic approach through the application of Interfaces Aesthetic Measurement (IAM) against the use of the environmental aesthetic method through the assessment of people preferences.

\section{Research objectives and methods}

The focus of the research areas is located in two commercial street corridors, Soekarno-Hatta and Borobudur Street corridors, in Malang City, Indonesia. Soekarno-Hatta and Borobudur Street corridors are a provincial street which is also the main connecting street from the north and east to the western region of Malang City. These corridors are a commercial area that has grown rapidly in new areas since the construction of a connecting bridge to MT. Haryono Street (as a link to the North-West region of Malang City). This strategic position led to both the provincial street corridor grew into a strategic area for the development of commercial functions, one of which is the restaurant business. This advantageous position is also strengthened by the existence of the educational function around the corridors. Public and private college with a significant number of students grew alongside the street corridors, i.e. Brawijaya University, Brawijaya Polytechnic, Widya Gama University, and STIE Malang Kucecwara College. The deployment of the restaurant facility tends to be concentrated in the area of education facility, especially around the college area. A significant increase in the number of students has also indicated a significant shift in the target visitors of the restaurant facility in both corridors that targeted to the college student. This circumstance is increasingly triggering a rapid growth of restaurant facilities along both corridors. The growth of restaurant facility has a variety of architectural styles that play a role in shaping the visual aesthetic in SoekarnoHatta and Borobudur Street corridors. Three influential factors, a strategic location which is adjacent to college facilities, the growth of new commercial areas, and the majority of customers which predominantly students and young people, stimulate the emergence various types of the visual appearance of the building facade restaurants along both corridor. Similarly, young entrepreneurs that dominated the migrants in both areas, has an important role in the proliferation of diversity the visual appearance of the building facade that inclined toward an attractive and contemporary facade. The region and the object of research can be seen on the following map.

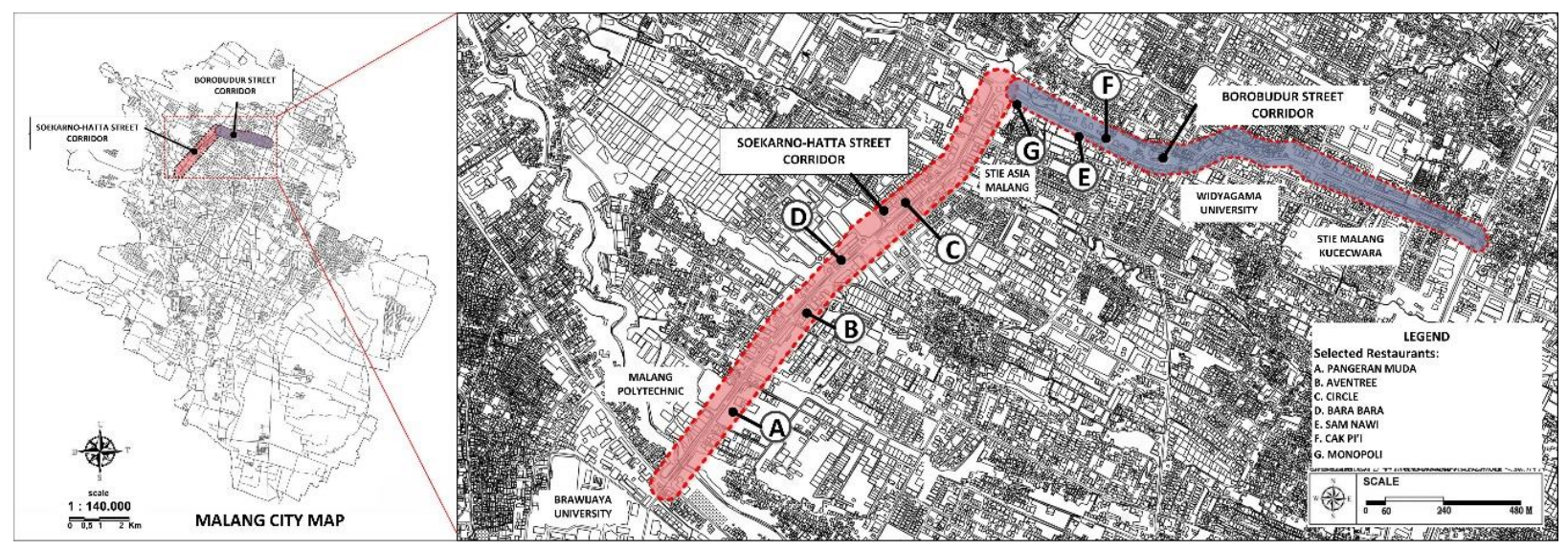

Fig. 1. Map of the research area 


\subsection{Public preferences method}

The research population was the entire community of Malang City consisting of the public, academics, practitioners, and government. Four groups of respondents are expected to represent the majority of public opinion in Malang City. Age of respondents was required aged 18 years and over in order to understand the questions and capable to providing an assessment of the visual quality of the restaurant's facade objectively.

Sampling methods used non-probability sampling with purposive sampling technique. This technique does not provide the same possibilities for each element of the population to be selected into the sample (Nasution, 1995). Sampling was performed by taking into account the factors of knowledge, confidence, and experience of researchers and used as consideration for determining the members of the population to be selected as a sampling. Research sampling consists of two groups of 30 respondents among the public of Malang City on both corridors and 30 respondents from practitioners and academics in the fields of architecture consisting of architecture students, lecturers of architecture, as well as the architect practitioners.

Variables used in this research are intended to concentrate the respondents' assessment against the visual quality of the restaurant's facade along Soekarno-Hatta and Borobudur Street corridors. The questionnaire uses a research's variable which refers to the 13 variables of image aesthetic value in the entity scale (Ngo et al, as cited in Purnomo, 2009) which has been combined with semantic scale, as shown in table 1.

Table 1. Research variables combined with the semantic scale

\begin{tabular}{clcc}
\hline \multirow{2}{*}{ No. } & \multicolumn{1}{c}{ Variable } & \multicolumn{2}{c}{ Semantic scale } \\
\cline { 3 - 4 } & & $(-)$ & $(+)$ \\
\hline 1. & Measure of balance & Unbalanced & Balanced \\
2. & Measure of equilibrium & Contrast & Conformable \\
3. & Measure of symmetry & Asymmetry & Symmetry \\
4. & Measure of sequence & No sequence & Sequential \\
5. & Measure of cohesion & Unintegrated & Integrated \\
6. & Measure of unity & No unity & Unity \\
7. & Measure of proportion & Disproportionate & Proportional \\
8. & Measure of simplicity & Complex & Simple \\
9. & Measure of density & Transparent & Massive \\
10. & Measure of regularity & Chaotic & Regular \\
11. & Measure of economy & Ineffective & Effective \\
12. & Measure of homogeneity & Unharmonious & Harmony \\
13. & Measure of rhythm & Monotonous & Dynamic \\
\hline
\end{tabular}

Semantic scale measurement refers to the method of Thurstone. The measurement is intended to analyze the preferences of the public on the quality of the visual appearance of the restaurant's facade in Soekarno-Hatta and Borobudur Street corridors. This scale contains items organized by level of intensity, from high to low (Nasution, 1995). Respondents will be asked to put each item statement, in one of the seven category scales. The neutral point is in grades 4 , while the average value of $>4$ has indications tend to be positive and for the average value which $<4$ have indications tend to be negative. Subsequently, the result of public preferences was conducted Independent Sample T-test in order to compare the opinions of the two different groups, i.e. the public with the professionals (practitioners and academics in the field of architecture).

\subsection{Computational aesthetic method}

Image analysis of entity scale utilized a software application of Interface Aesthetic Measurement (IAM). Interface Aesthetic (IA) is a part of a field of science called 'Computational Aesthetics'. Measurement of IA, either digital or emerging as the interface on a monitor, divided into entities with specific characteristics and attributes. There are 13 aesthetic variables that can be measured based on the attributes of an interface entity (Ngo et al, as cited Purnomo, 2009), i.e. measure of balance (BM), measure of equilibrium (EM), measure of sequence (SQM), measure of cohesion (CM), measure of unity (UM), measure of proportion (PM), measure of simplicity (SMM), measure of regularity (RM), measure of homogeneity(HM), measure of rhythm (RHM), measure of symmetry 
(SYM), measure of density (DM), measure of economy (ECM). All the 13 aesthetic variables were combined into one aesthetic index, namely a measure of order and complexity (OM). The calculation formula of the 13 aesthetic variables is based on information contained in an entity that is the relative position of the entity in an interface in the form (Xc, Yc), and the size of the vertical and horizontal entities that can also be represented by a set of points that form the boundary entities (Xs, Ys). The formula was created based on the details of the calculation step of Interface Aesthetic variables that have been translated into a Visual Basic script and it has been integrated with the Visual Basic application format by Purnomo (Purnomo, 2009). The form of entities in the interface and the formula used to calculate the interface aesthetic variables and the interface aesthetic index can be seen in the figure below.
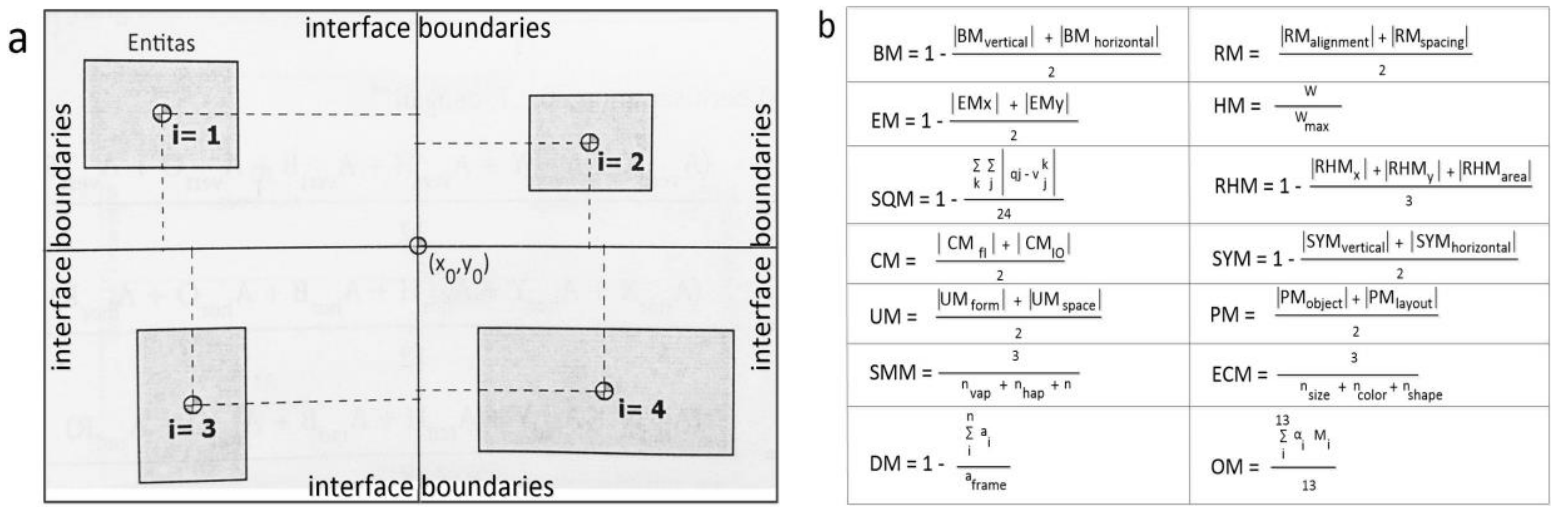

Fig.2. (a) The form of entities in the interface; (b) The formula of interface aesthetic variables

The measurement variables of computational aesthetic and the assessment variables of public preferences method refer to the 13 variables of image aesthetic value in the entity scale (Ngo et al, as cited in (Purnomo, 2009)).

\section{Results and discussion}

\subsection{Respondents' perceptions of building stimuli}

\subsubsection{Characteristics of respondents}

Respondents were taken from two groups of people, i.e. 30 respondents from the public and 30 respondents from the professional group consisting of academics and practitioners. Public respondents were taken from people who lived, activity and across the Soekarno-Hatta and Borobudur Street corridor. Meanwhile, the professional group consisted of practitioners (33.3\%) and academics (66.7\%) from the field of architecture. The academic group was divided into two groups: students (33.3\%) and lecturers (33.3\%). Student respondents were selected from students at the final level of study. These students were assumed to have had sufficient knowledge and science in the field of Architecture.

\subsubsection{Building stimuli}

At the initial stage, the data collection of the restaurant located along the Soekarno-Hatta and Borobudur Street corridor were performed to obtain a building stimuli. Building stimuli of restaurant have to fulfill the selection criteria as follows:

1. The restaurant building that is a stand-alone (not inside a mall, hotel, resort, nor other commercial places)

2. The restaurant building that does not include Brand Image International (such as Mc Donald's, KFC, Pizza Hut, etc.) 
3. The restaurant building that does not join the other functions (not a building over the function) and not part of the complex shapes (unless the building has a strong visual character and or had a square measure of more than two units of shophouses)

4. The restaurant building that is a permanent building

The initial selection process resulted in 13 restaurants at Soekarno-Hatta Street corridor and 6 restaurants at Borobudur Street corridor. A further process was the categorization of 19 restaurants based on the architectural style of building façade and the type of restaurants classification. The categorization on the architectural style of building facade was divided into modern tropical and modern minimalist, while the categorization of the type of restaurants classification was divided into Family Restaurant and Cafe Restaurant. Eventually, this categorization produced seven restaurant building that represents as a building stimuli (see Table 2 and figure 3).

Table 2. Categorization of selected restaurants

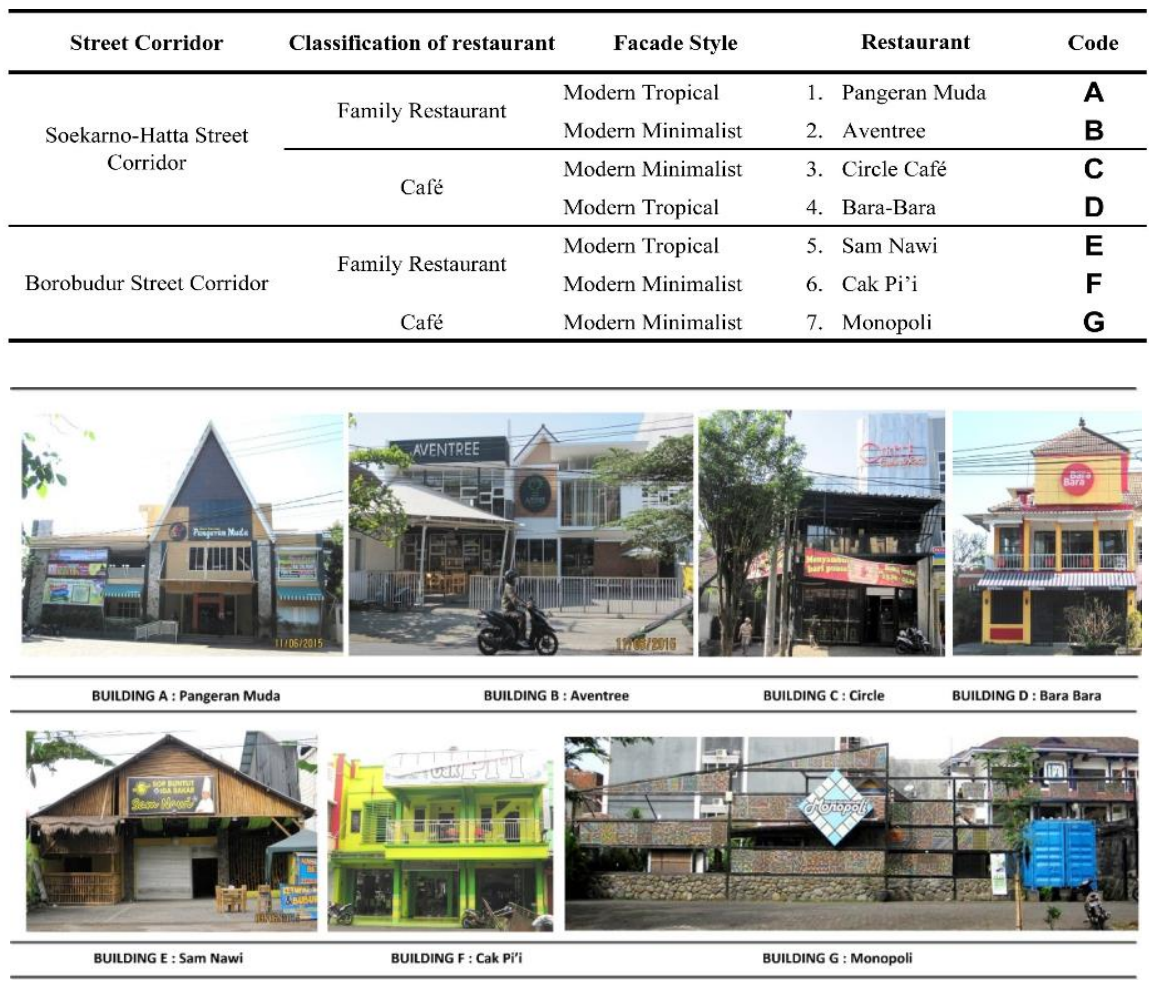

Fig. 3. Photos of selected restaurants

\subsubsection{Assessment of respondents to the building stimuli}

The seven restaurants selected were used as a building stimuli for the respondent's assessment based on 13 semantics scale. Based on the evaluation of both respondent groups to the whole building stimuli, an aesthetic facade of seven buildings stimuli tends to show a positive assessment ( $>4.0)$. An assessment result of the public groups showed that the composition of the elements on the building facade of seven building stimuli has a positive aesthetic so that the whole assessment of each variable in the semantic scale assessed positively. Meanwhile, the assessment results based on a professional group showed negative assessment $(<4.0)$ on several variables in each building stimuli. The first highest of negative assessment contained in the measurement variable of rhythm (monotonous-dynamic), i.e. the building stimuli C, D, E, and F (57.14\%). The second highest of negative assessment contained in the measurement variable of symmetry (the symmetry-asymmetry), i.e. the building stimuli $\mathrm{A}, \mathrm{B}$, and $\mathrm{G}(42.86 \%)$. The third highest of negative assessment contained in the measurement variable of density 
(transparent-massive), i.e. the building stimuli B and C (28.57\%). Nevertheless, an overall average of assessment in the professional group tends to show a positive assessment.

In order to compare the opinions between the two groups of respondents, the assessment results of both groups of respondents were performed a t-test through the independent sample t-test. If the p-value (significance t-test) greater than $\alpha(\alpha=0.05)$, it can be inferred the existence of common ground between the two groups of respondents. And if the p-value (significance test $t$ ) is smaller than $\alpha(\alpha=0.05)$, it can be inferred the existence of differences in opinion between both groups of respondents. T-test results in the independent sample t-tests which performed on each of the variables showed the existence of common ground by $79.12 \%$ and contained a difference of opinion by $20.88 \%$ between the public group and professional group on several variables. While the results of t-test in the independent sample t-tests which performed on all variables in each building stimuli, showed the existence of common ground on the building stimuli A, B, C, E, F, and G $(85.71 \%)$ and contained a different opinion on the building stimuli D (14.29\%). The overall result of the respondents' assessment and the overall result of the independent sample t-tests can be seen in table 3 and table 4 .

Table 3. The overall result of the respondents' assessment

\begin{tabular}{|c|c|c|c|c|c|c|c|c|c|c|c|c|c|c|c|c|c|c|c|c|c|c|c|c|c|c|c|c|c|}
\hline \multirow{4}{*}{ No } & \multirow{4}{*}{ Semantic Scale } & \multicolumn{28}{|c|}{ Building } \\
\hline & & \multicolumn{4}{|c|}{ A } & \multicolumn{4}{|c|}{ B } & \multicolumn{4}{|c|}{ C } & \multicolumn{4}{|c|}{ D } & \multicolumn{4}{|c|}{ E } & \multicolumn{4}{|c|}{$\mathbf{F}$} & \multicolumn{4}{|c|}{ G } \\
\hline & & \multicolumn{2}{|c|}{ Public } & \multicolumn{2}{|c|}{ Professional } & \multicolumn{2}{|c|}{ Public } & \multicolumn{2}{|c|}{ Professional } & \multicolumn{2}{|c|}{ Public } & \multicolumn{2}{|c|}{ Professional } & \multicolumn{2}{|c|}{ Public } & \multicolumn{2}{|c|}{ Professional } & \multicolumn{2}{|c|}{ Public } & \multicolumn{2}{|c|}{ Professional } & \multicolumn{2}{|c|}{ Public } & \multicolumn{2}{|c|}{ Professional } & \multicolumn{2}{|c|}{ Public } & \multicolumn{2}{|c|}{ Professional } \\
\hline & & $(-)$ & $(+)$ & $(-)$ & $(+)$ & $(-)$ & $(+)$ & $(-)$ & $(+)$ & $(-)$ & $(+)$ & $(-)$ & $(+)$ & $(-)$ & $(+)$ & $(-)$ & $(+)$ & $\theta$ & $(+)$ & $(-)$ & $(+)$ & $(-)$ & $(+)$ & $(-)$ & $(+)$ & $(-)$ & $(+)$ & $\theta$ & $(+)$ \\
\hline 1. & Unbalanced - Balanced & - & 4.7 & 3.63 & - & - & 4.8 & - & 4.4 & - & 4.53 & - & 4.5 & - & 5.23 & - & 4.07 & - & 4.93 & - & 5.33 & - & 5.23 & - & 4.23 & - & 4.77 & - & 4.3 \\
\hline 2. & Contrast - Conformable & - & 4.56 & - & 4.13 & - & 5.1 & - & 4.73 & - & 4.8 & - & 4.1 & - & 5.1 & - & 4.3 & - & 4.8 & - & 4.9 & - & 4.93 & - & 4.03 & - & 4.7 & - & 4.13 \\
\hline 3. & No sequence - Sequential & - & 4.36 & 3.7 & - & - & 4.77 & - & 4.37 & - & 4.5 & - & 4.23 & - & 4.8 & - & 4.53 & - & 4.37 & - & 4.6 & - & 4.57 & - & 4.57 & - & 4.7 & - & 4.63 \\
\hline 4. & Unintegrated - Integrated & - & 4.73 & - & 4.43 & - & 4.93 & - & 4.43 & - & 4.53 & - & 4 & - & 5 & - & 4.4 & - & 4.5 & - & 4.5 & - & 4.77 & - & 4.3 & - & 4.7 & - & 4.5 \\
\hline 5. & No unity - Unity & - & 4.97 & - & 4.53 & - & 5.03 & - & 4.63 & - & 5.03 & 3.93 & - & - & 5.1 & - & 4.33 & - & 4.73 & - & 4.5 & - & 4.8 & - & 4.23 & - & 5 & - & 4.43 \\
\hline 6. & Disproportionate - Proportional & - & 4.83 & - & 4.43 & - & 4.7 & - & 5.1 & - & 4.7 & - & 4.23 & - & 4.9 & - & 4.83 & - & 4.33 & - & 4.93 & - & 4.73 & - & 4.8 & - & 4.73 & - & 4.9 \\
\hline 7. & Complex - Simple & - & 4.33 & - & 4.47 & - & 4.33 & 3.57 & - & - & 4.4 & - & 4.8 & - & 4.7 & - & 4.5 & - & 4.8 & - & 5.87 & - & 4.47 & - & 4.6 & - & 4.13 & - & 4.03 \\
\hline 8. & Chaotic - Regular & - & 4.43 & - & 4.57 & - & 4.23 & - & 4.5 & - & 4.2 & - & 4.5 & - & 4.63 & - & 4.83 & - & 4.53 & - & 4.7 & - & 4.73 & - & 4.9 & - & 4.6 & - & 4.73 \\
\hline 9. & Unharmonious - Harmony & - & 4.63 & - & 4.53 & - & 5.07 & - & 4.73 & - & 4.47 & - & 4.1 & - & 4.7 & - & 4.43 & - & 4.2 & - & 4.37 & - & 4.53 & - & 4.7 & - & 4.57 & - & 4.73 \\
\hline 10. & Monotonous - Dynamic & - & 4.4 & - & 4.13 & - & 4.93 & - & 4.63 & - & 4.5 & 3.36 & - & - & 4.63 & 3.83 & - & - & 4.13 & 3.27 & - & - & 4.6 & 3.5 & - & - & 4.57 & - & 4.57 \\
\hline 11. & Asymmetry - Symmetry & - & 4.6 & 3.23 & - & - & 4.67 & 3.33 & - & - & 4.63 & - & 4.56 & - & 4.83 & - & 4.2 & - & 4.9 & - & 5.33 & - & 4.4 & - & 4.4 & - & 4.6 & 3.8 & - \\
\hline 12. & Transparent - Massive & - & 4.7 & - & 4.77 & - & 4.17 & 2.87 & - & - & 4.27 & 2.43 & - & - & 4.57 & - & 4.43 & - & 4.4 & - & 4.03 & - & 4.23 & - & 4.5 & - & 4.4 & - & 4.23 \\
\hline 13. & Ineffective-Effective & - & 4.36 & - & 4.86 & - & 4.3 & - & 4.53 & - & 4.73 & - & 4.33 & - & 4.7 & - & 4.5 & - & 4.27 & - & 4.3 & - & 4.6 & - & 4.83 & - & 4.4 & - & 4.53 \\
\hline \multicolumn{2}{|r|}{ the average of the positive value } & - & 4.59 & - & 4.26 & - & 4.69 & - & 4.29 & - & 4.56 & - & 4.08 & - & 4.84 & - & 4.4 & - & 4.53 & - & 4.66 & - & 4.66 & - & 4.43 & - & 4.61 & - & 4.43 \\
\hline & Total average & & 4.43 & $(+)$ & & & 4.4 & $(+)$ & & & 4.32 & $(+)$ & & & 4.62 & & & & 4.59 & $9(+)$ & & & 4.55 & $(+)$ & & & & $(+)$ & \\
\hline
\end{tabular}

Table 4. The overall result of the independent sample $t$ tests

\begin{tabular}{|c|c|c|c|c|c|c|c|c|c|}
\hline \multirow{3}{*}{ No } & \multirow{3}{*}{ Variable } & \multirow{3}{*}{ Semantic Scale } & \multicolumn{7}{|c|}{ Value of Significance T-test } \\
\hline & & & \multicolumn{7}{|c|}{ Building } \\
\hline & & & A & $\mathbf{B}$ & $\mathbf{C}$ & D & $\mathbf{E}$ & $\mathbf{F}$ & $G$ \\
\hline 1. & Measure of balance & Unbalanced - Balanced & 0.002 & 0.252 & 0.934 & 0.004 & 0.364 & 0.004 & 0.286 \\
\hline 2. & Measure of equilibrium & Contrast - Conformable & 0.265 & 0.190 & 0.049 & 0.032 & 0.790 & 0.023 & 0.163 \\
\hline 3. & Measure of sequence & No sequence - Sequential & 0.06 & 0.291 & 0.481 & 0.371 & 0.499 & 1.000 & 0.85 \\
\hline 4. & Measure of cohesion & Unintegrated - Integrated & 0.378 & 0.132 & 0.117 & 0.075 & 1.000 & 0.165 & 0.586 \\
\hline 5. & Measure of unity & No unity - Unity & 0.245 & 0.252 & 0.006 & 0.035 & 0.470 & 0.145 & 0.131 \\
\hline 6. & Measure of proportion & Disproportionate - Proportional & 0.281 & 0.250 & 0.221 & 0.837 & 0.098 & 0.847 & 0.653 \\
\hline 7. & Measure of simplicity & Complex - Simple & 0.677 & 0.025 & 0.336 & 0.541 & 0.008 & 0.71 & 0.789 \\
\hline 8. & Measure of regularity & Chaotic - Regular & 0.705 & 0.513 & 0.508 & 0.556 & 0.681 & 0.582 & 0.703 \\
\hline 9. & Measure of homogenity & Unharmonious - Harmony & 0.755 & 0.329 & 0.289 & 0.388 & 0.663 & 0.617 & 0.657 \\
\hline 10 . & Measure of rhythm & Monotonous - Dynamic & 0.473 & 0.424 & 0.004 & 0.033 & 0.034 & 0.008 & 1.000 \\
\hline 11. & Measure of symmetry & Asymmetry - Symmetry & 0.001 & 0.001 & 0.863 & 0.071 & 0.259 & 1.000 & 0.04 \\
\hline 12. & Measure of density & Transparent - Massive & 0.838 & 0.001 & 0.001 & 0.674 & 0.328 & 0.477 & 0.664 \\
\hline 13. & Measure of economy & Ineffective - Effective & 0.167 & 0.525 & 0.337 & 0.561 & 0.927 & 0.528 & 0.751 \\
\hline \multicolumn{3}{|c|}{ Independent Sample T-Test on the overall Semantics scale } & 0.140 & 0.081 & 0.077 & 0.046 & 0.622 & 0.325 & 0.479 \\
\hline
\end{tabular}

\subsubsection{A comparative analysis of respondents' assessment of each building stimuli}

The average result of the overall assessment of respondents in each of the buildings stimuli can be concluded that the respondents presented a positive assessment against the overall of the building stimuli as indicated by the 
general average assessment above the value of 4 (see table 5). Based on the results of the combined average assessment of respondents to the 13 semantic scales on the building facade in each buildings stimuli, then the buildings stimuli can be sorted from highest to lowest value.

Table 5. Comparison value of the aesthetic facade of respondents' assessment

\begin{tabular}{cccc}
\hline \multirow{2}{*}{ Building } & \multicolumn{2}{c}{$\begin{array}{c}\text { Average value of } \\
\text { respondents' assessment }\end{array}$} & $\begin{array}{c}\text { General } \\
\text { average }\end{array}$ \\
\cline { 2 - 3 } & Public & Professional & \\
\hline Building A & 4.59 & 4.26 & 4.43 \\
Building B & 4.69 & 4.29 & 4.49 \\
Building C & 4.56 & 4.08 & 4.32 \\
Building D & 4.84 & 4.40 & 4.62 \\
Building E & 4.53 & 4.66 & 4.59 \\
Building F & 4.66 & 4.43 & 4.55 \\
Building G & 4.61 & 4.43 & 4.52 \\
\hline
\end{tabular}

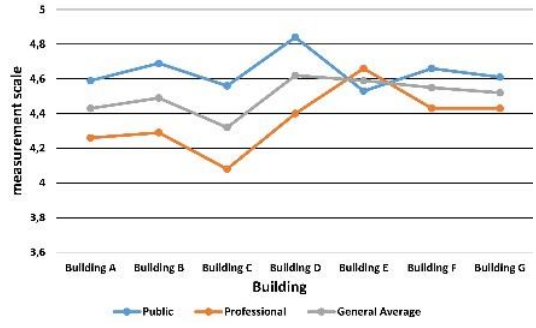

Based on the analysis Independent Sample T-Test of the overall semantic scale of each building stimuli, it can be seen the differences in assessment between respondents of the public group and professional group in the building stimuli D. The difference in the assessment of some of the variables is assumed the differences in knowledge and level of education among the public group and professional group. This leads to the gap of understanding and viewpoints against the each variable, thus resulting in different assessments. Nevertheless, the results of the overall assessment tend to show similar assessments between the two groups of respondents. The result of Independent Sample T-Test on the overall semantic scale of each building stimuli can be seen in table 6 .

Table 6. The result of Independent Sample T-Test on the overall semantic scale of each building stimuli

\begin{tabular}{llllll}
\hline \multicolumn{1}{c}{ Restaurant } & P-value & $\begin{array}{c}\text { The similarities or the differences of } \\
\text { assessment among the respondent* }\end{array}$ & $\begin{array}{c}\text { Measurement variables which have a } \\
\text { different assessment among the respondent }\end{array}$ \\
\hline Building A & : Pangeran Muda & 0.140 & $(\mathrm{p}$-value $>\alpha)$ & have similarities & Balance, Symmetry \\
Building B & : Aventree & 0.081 & $(\mathrm{p}$-value $>\alpha)$ & have similarities & Simplicity, Symmetry, Density \\
Building C & : Circle & 0.077 & $(\mathrm{p}$-value $>\alpha)$ & have similarities & Equilibrium, Unity, Rhythm, Density \\
Building D & : Bara Bara & 0.046 & $(\mathrm{p}$-value $<\alpha)$ & have differences & Balance, Equilibrium, Unity, Rhythm \\
Building E & : Sam Nawi & 0.622 & $(\mathrm{p}$-value $>\alpha)$ & have similarities & Simplicity, Rhythm \\
Building F & : Cak Pi'i & 0.325 & $(\mathrm{p}$-value $>\alpha)$ & have similarities & Balance, Equilibrium, Rhythm \\
Building G & : Monopoli & 0.479 & $(\mathrm{p}$-value $>\alpha)$ & have similarities & Symmetry \\
\hline$*(\alpha=0.05)$ & & & &
\end{tabular}

\subsection{Measurement of computational aesthetic}

Building facade of seven restaurants selected as the building stimuli was analyzed one by one using the application of Interface Aesthetic Measurement (IAM). This application analyzes the attributes of entities owned by an interface on the building facade image in the 13 variables of aesthetic. Those variables are the similar variables that are used in the method of public preferences. Before using the application of IAM, in the early stage portrayal of the facade of each building were performed as a two-dimensional of an image file. In the process of image analysis, each image of building facade must be identified the entity of each diversity of geometric shapes. Once the process of identification of geometric entities is completed, it can be directly generated the aesthetic measurement value of each 13 variables of aesthetic. In the final calculation, the application generates the value of OM (Order / complexity Measure) which indicates the final value of complexity on each building facade. The identification results of geometry entity on each building facade and compilation of 13 aesthetic measurement values on the seven buildings stimuli can be seen in figure 4 and table 7 . 


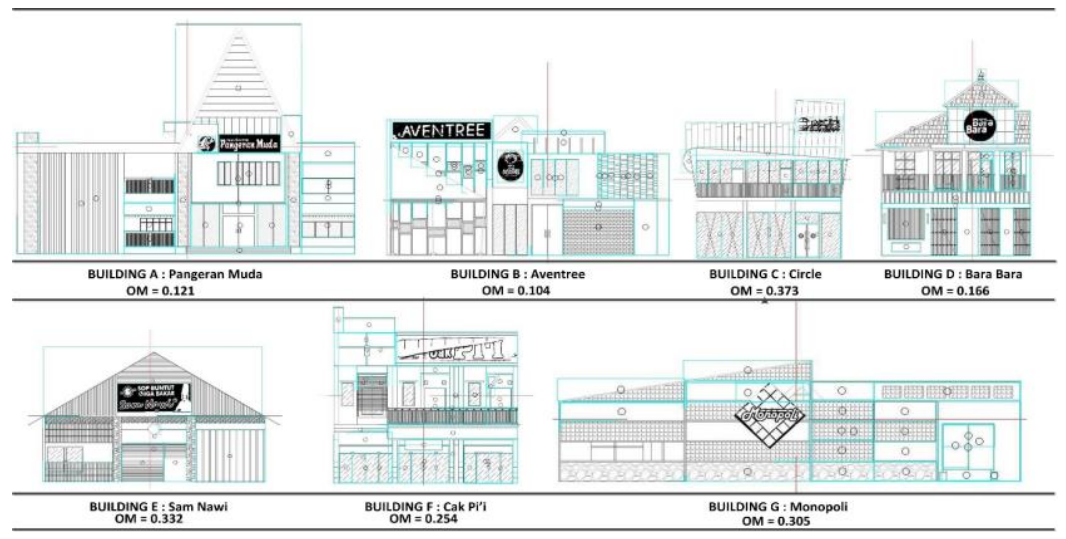

Fig. 4. The identification results of geometric entity on each building facade through Interface Aesthetic Measurement (IAM)

Table 7. The compilation of 13 aesthetic measurement values on the seven buildings stimuli

\begin{tabular}{|c|c|c|c|c|c|c|c|c|c|c|c|c|c|c|}
\hline Building & BM & EM & SYM & SQM & CM & UM & PM & SMM & DM & $\mathbf{R M}$ & ECM & HM & RHM & OM \\
\hline Building A & 0.505 & 0.994 & -0.622 & 0.25 & 0.738 & 0.349 & 0.865 & 3.030 & -0.072 & 0.263 & 0.037 & 9.911 & -1.763 & 0.121 \\
\hline Building B & 0.461 & 0.998 & -1.006 & 0.5 & 0.524 & 0.337 & 0.808 & 1.435 & 0.166 & 0.29 & 1.786 & 3.395 & -1.764 & 0.104 \\
\hline Building C & 0.568 & 0.997 & 0.237 & 0.75 & 0.635 & 0.365 & 0.883 & 2.189 & 0.101 & 0.308 & 0.027 & 3.776 & -7.542 & 0.373 \\
\hline Building D & 0.289 & 0.997 & -0.384 & 0.25 & 0.548 & 0.162 & 0.810 & 1.744 & 0.367 & 0.247 & 2.273 & 1.358 & -1.173 & 0.166 \\
\hline Building $\mathbf{E}$ & 0.516 & 0.994 & 0.275 & 0.25 & 0.686 & 0.507 & 0.791 & 3.488 & 0.404 & 0.163 & 4.762 & 4.724 & -0.352 & 0.332 \\
\hline Building F & 0.602 & 0.998 & -6.019 & 0.75 & 0.625 & 0.285 & 0.864 & 1.463 & -0.334 & 0.294 & 1.923 & 0.279 & -1.042 & 0.254 \\
\hline Building $\mathbf{G}$ & 0.598 & 0.999 & 0.156 & 0.5 & 0.494 & 0.275 & 0.558 & 0.027 & 0.459 & 0.309 & 3.448 & 1.189 & -0.450 & 0.305 \\
\hline \multicolumn{4}{|c|}{$\begin{array}{l}\mathrm{BM}=\text { Measure of balance } \\
\mathrm{EM}=\text { Measure of equilibrium } \\
\mathrm{SYM}=\text { Measure of symmetry } \\
\mathrm{SQM}=\text { Measure of sequence }\end{array}$} & \multicolumn{4}{|c|}{$\begin{array}{l}\mathrm{CM}=\text { Measure of cohesion } \\
\mathrm{UM}=\text { Measure of unity } \\
\mathrm{PM}=\text { Measure of proportion } \\
\mathrm{SMM}=\text { Measure of simplicity }\end{array}$} & $\begin{array}{l}\mathrm{DM}=\mathrm{M} \\
\mathrm{RM}=\mathrm{M} \\
\mathrm{ECM}=\mathrm{M} \\
\mathrm{HM}=\mathrm{M}\end{array}$ & sure of hor & $\begin{array}{l}\text { ity } \\
\text { arity } \\
\text { omy } \\
\text { ogeneity }\end{array}$ & & \multicolumn{3}{|c|}{$\begin{aligned} \text { RHM = } & \text { Measure of rhythm } \\
\text { OM } & \text { Measure of order/ } \\
& \text { complexity }\end{aligned}$} \\
\hline
\end{tabular}

According to the compilation of 13 aesthetic measurement values on the seven buildings stimuli, it can be seen the order of stimuli of the building that has the highest to the lowest value of OM. Building C (Circle Cafe) has the highest value of OM, while of the building B (Aventree) has the lowest value of OM.

\section{Conclusions and future work}

Research on the aesthetic evaluation of the restaurant's facade at Soekarno-Hatta and Borobudur Street corridor in Malang City resulted in two conclusions obtained from the assessment results of public preferences and the measurement result from the application of Interface Aesthetic Measurement (IAM). Subsequently, both results were compared in table 8 .

Table 8. The comparison results between the values of public preferences and the OM scores of computational aesthetic

\begin{tabular}{|c|c|c|c|c|}
\hline \multirow[b]{2}{*}{ Rank } & \multicolumn{2}{|c|}{ Public Preferences } & \multicolumn{2}{|c|}{ Computational Aesthetic } \\
\hline & $\begin{array}{l}\text { The order of the buildings from the } \\
\text { highest value to lowest value }\end{array}$ & Average Value & $\begin{array}{l}\text { The order of the buildings from the } \\
\text { highest score to lowest score }\end{array}$ & OM Score* \\
\hline 1. & Building D & 4.62 & Building $\mathrm{C}$ & 0.373 \\
\hline 2. & Building E & 4.59 & Building E & 0.332 \\
\hline 3. & Building $\mathrm{F}$ & 4.55 & Building G & 0.305 \\
\hline 4. & Building G & 4.52 & Building $\mathrm{F}$ & 0.254 \\
\hline 5. & Buildèng $\mathrm{B}$ & $4.49^{-2.20}$ & Building D... & .0 .166 \\
\hline 6. & Building A & 4.43 & Building $\mathrm{A}$ & 0.121 \\
\hline 7 & Building $\mathrm{C}^{-}$ & 4.32 & 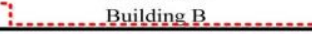 & $0.104 \ldots$ \\
\hline
\end{tabular}


Based on these results, it can be inferred there are differences in the results of the public preference assessment with the measurement of computational aesthetics. Nevertheless, based on the value or score order of both methods, obtained the similarity of the order value/ score in the group of buildings in a specific range of value. There are two buildings that have an assessment result in contrasts to the measurement results, which is building $\mathrm{C}$ (Circle Cafe) and building D (Bara-bara Cafe). The assessment results of the public preferences show that building D was ranked on the highest value and building $\mathrm{C}$ was ranked on the lowest value, while the computational aesthetic measurement results show that buildings $\mathrm{C}$ was ranked in the highest value and building $\mathrm{D}$ was ranked in the group of the lowest score. Moreover, it can be stated that two of the seven buildings $(28.57 \%)$ have a difference in value between public preferences with a computational aesthetic method. Meanwhile, five of the seven buildings $(71.43 \%)$ had an order value of almost equal between public preferences with a computational aesthetic method. The emergence of the differences in value between the two approaches has strengthened the notion of Leder that respondents' perception aspects as part of the internal process of human in the aesthetic assessment of public preference approaches (Leder, Belke, Oeberst, \& Augustin, 2004). Regarding the result, Interface Aesthetic Measurement (IAM) applications could not be used as a tool to measure the aesthetic value of a building independently.

This study specifically concludes a comparative opinion among the general public with professional groups about the aesthetic value of the building facade of the restaurant on a commercial street corridor, specifically on Soekarno-Hatta street and Borobudur street. Whilst in general, these results perform a test and examine the level of accuracy as well as the successful use of Interface Aesthetic Measurement (IAM) applications in measuring the aesthetic value of commercial building facade through computational measurement, which is comparable to the public preferences method.

Research on the aesthetic evaluation of building facade in the street corridor has to carry out continuously in order to control and maintain a visual continuity of urban space and ensuring the creation of a valuable aesthetic experience of urban space and convenient for the public. Further research related to the aesthetic evaluation of building facade can be performed on the other commercial buildings. Moreover, it is necessary to carry out an improvement or development of the computational application in measuring the aesthetic quality of the building facade.

\section{References}

Cass, R. C., \& Hershberger, R. G. (1972). Further Towards a Set of Semantic Scales to Measure the Meaning of Design Environments. Arizona State University.

Ching, F. D. K. (2012). A visual dictionary of architecture. Wiley.

Gonzalez, R. C. (2002). Digital Image Processing. Leonardo (Vol. 14). Prentice Hall.

Leder, H., Belke, B., Oeberst, A., \& Augustin, D. (2004). A model of aesthetic appreciation and aesthetic judgments. British Journal of Psychology, 95(4), 489-508.

Lynch, K. (1960). The image of the city. MIT Press.

Nasar, J. L. (1988). Environmental aesthetics : theory, research, and applications. Ohio: Cambridge University Press.

Nasar, J. L. (1998). The evaluative image of the city. Sage Publications.

Nasution, S. (1995). Metode research (penelitian ilmiah). Jakarta : Bumi Aksara.

Porteous, J. D. (John D. (1996). Environmental aesthetics : ideas, politics and planning. Routledge.

Purnomo, A. B. (2009). Teknik Kuantitatif untuk Arsitektur dan Perancangan Kota Disertai dengan Contoh-contoh. Jakarta: Jakarta Rajawali Pers.

Rubenstein, H. M. (1980). A guide to site and environmental planning. Wiley.

Smardon, R. C., Palmer, J. F., \& Felleman, J. P. (1986). Foundations for visual project analysis. Wiley.

Vining, J., \& Stevens, J. J. (1986). The Assessment of Landscape Quality: Methodological Considerations. In R. C. Smardon, J. F. Palmer, \& J. P. Felleman (Eds.), Foundation for Visual Project Analysis (pp. 167-186). New York: John Wiley \& Son Inc.

Wohlwill, J. F. (1976). Environmental Aesthetics: The Environment as a Source of Affect. In I. Altman \& J. F. Wohlwill (Eds.), Human Behavior and Environment (pp. 37-86). Boston, MA: Springer US. 